\title{
O projetor de gotas e suas diversas abordagens interdisciplinares no Ensino de Física
}

The water drop projector and its various approaches in Physics Teaching

\author{
Marcel Phillippi Dorta*1, Edi Carlos Pereira de Sousa ${ }^{1}$, Mikiya Muramatsu ${ }^{2}$ \\ ${ }^{1}$ Programa de Pós-Graduação em Física, Instituto de Física, Universidade de São Paulo, São Paulo, SP, Brasil \\ ${ }^{2}$ Instituto de Física, Universidade de São Paulo, São Paulo, SP, Brasil
}

Recebido em 5 de maio de 2016. Revisado em 12 de junho de 2016. Aceito em 15 de junho de 2016

\begin{abstract}
Neste trabalho é apresentado um experimento didático e de baixo custo, de forma simples e intuitiva, chamado de projetor de gotas. Este experimento pode ser uma alternativa mais eficiente ao uso de microscópios para a observação de microrganismos em sala de aula, pois, pode ser visualizado por diversas pessoas de uma só vez, além de seus componentes serem de fácil acesso. Os fundamentos físicos do experimento residem nos conceitos de óptica e podem ser abordados de forma dinâmica e interativa, favorecendo a discussão sobre a interação da luz com a matéria orgânica e a natureza ondulatória e geométrica envolvida. O projetor de gotas pode ser utilizado em aulas de diferentes disciplinas tanto de exatas como biológicas, em nível de ensino fundamental, médio e superior. Inicialmente, mostra-se a metodologia experimental assim como, sugestões de materiais alternativos para montagem do experimento. Em seguida, descreve-se a física envolvida para a formação das imagens, para então demonstrar diversas aplicações que podem ser feitas em sala de aula. O foco principal do trabalho foi o de explorar as diversas possibilidades de abordagens que podem ser feitas com o experimento, a fim de mostrar seu alcance e facilidade de interação da física com outras áreas de conhecimento, como por exemplo a biologia.
\end{abstract}

Palavras-chave: projetor de gotas, óptica, luz, formação de imagens, calor.

In this work it is presented a didactic and low-cost experiment, in a simple and intuitive way, called water drop projector. This experiment can be a more efficient alternative to the use of microscopes for observing microorganisms in the classroom, because it can be viewed by several people at once and its components are easily accessible. The physical foundation of the experiment is based on optical concepts and can be performed in a dynamic and interactive way, providing a discussion about light interaction with organic matter and the wave and geometrical features involved. The water drop projector can be used in classes of different disciplines both exact and biological, in primary, secondary and higher school levels. Initially, the experimental methodology is shown, as well as suggestions on alternatives material for experimental setting. Next, the physics involved in image formation is described and several applications that can be done in the classroom are demonstrated. The main goal of the work was to explore several approaches that can be done with the experiment, in order to show its scope and easiness to interact physics with other areas of knowledge, such as biology.

Keywords: drops projector, optics, light, image formation, heat.

\section{Introdução}

A luz é um fenômeno ondulatório de natureza física, que faz parte da nossa vida desde sempre e, independente do que fazemos, ela está presente no nosso dia a dia. Praticamente tudo o que sabemos sobre

*Endereço de correspondência: mdorta@if.usp.br o universo e a vida na Terra é graças à existência da luz. Para entendermos a origem do universo, a formação do sistema solar, a existência de vida na terra entre diversos outros acontecimentos, é necessário conhecermos as características e principais propriedades dessa onda eletromagnética, a luz, que é o nosso principal meio de comunicação com o 
universo [1,2]. Não é por acaso que, nos últimos 20 anos, 14 pesquisadores foram agraciados com o prêmio Nobel de Física por pesquisas na área de óptica e fotônica, áreas essas que se dedicam ao estudo de propriedades e características da luz e suas interações [3].

Atualmente, no sistema educacional brasileiro, o estudo das propriedades da luz em geral ocorre na $2^{a}$ série do ensino médio na disciplina de física. Entretanto, grande parte do conhecimento que é transmitido aos alunos nesse período é sobre óptica geométrica [4]. Pouco se ensina sobre óptica física e os fenômenos ondulatórios envolvidos. Tendo em vista que diversos fenômenos da natureza essenciais para a vida na terra ocorrem graças às propriedades ondulatórias da luz, seu estudo não deveria se restringir apenas às aulas de física, e sim de diversas outras disciplinas, como química, biologia, entre outras. $\mathrm{Na}$ biologia, por exemplo, existem diversos fenômenos que só podem ser entendidos pelo estudo da luz e suas interações. Pensando nisso, o presente artigo se propõe a apresentar um experimento didático capaz de fazer uma interface entre física e biologia, além de poder discutir diversos fenômenos, tanto de óptica geométrica quanto física. O experimento em questão leva o nome de projetor de gotas, e foi primeiramente descrito no trabalho de Planinsic, 2001 [5]. Nele o autor basicamente utilizou um laser e uma gota de água para realizar o experimento. No decorrer do texto, iremos detalhar todo o processo de montagem experimental e a teoria envolvida, para daí então, propor diversas aplicações em sala de aula. Com isso, pretendemos demonstrar que um experimento de baixo custo e de fácil execução pode contribuir para uma abordagem interdisciplinar, sendo possível discutir diversos assuntos de forma dinâmica e ativa. Esse experimento tem sido divulgado pelo grupo Arte e Ciência do Instituto de Física da USP em várias escolas de ensino fundamental e médio na cidade de São Paulo. O experimento vem despertando a curiosidade de jovens e crianças pela ciência.

\section{Descrição do Experimento}

\subsection{Montagem e observação}

$\mathrm{O}$ aparato experimental consiste basicamente de uma fonte laser de $50 \mathrm{~mW}$ de potência, seringa plástica descartável, suporte confeccionado em madeira ou material similar para a seringa e, por fim, amostras de água contendo os microrganismos a serem estudados. O interessante é coletar amostras de microrganismo vivos, para que no momento da ampliação da imagem seja possível visualizar seu movimento. As amostras de água podem conter microrganismos com tamanhos médios em torno de 0.1 $\mathrm{mm}$ a $0.3 \mathrm{~mm}$.

A Fig. 1 ilustra a montagem do aparato experimental. Nessa ilustração, temos um suporte de madeira no qual a seringa fica presa com o bico suspenso para baixo. Pode-se utilizar diversos outros tipos de suportes para apoiar a seringa, tais como: livros, copos, caixas, garrafas pet furadas, etc. O imprescindível é manter a altura da seringa estável durante a realização do experimento. A fonte laser é ajustada em um suporte vertical, que consiste de um tripé flexível, o qual permite regular a posição e altura do feixe. Durante a realização do experimento foi utilizada a fonte laser mostrada na Fig. 1. A mesma possui comprimento de onda de $532 \mathrm{~nm}$ (cor verde). É possível utilizar um feixe laser com comprimento de onda $650 \mathrm{~nm}$ (cor vermelha), porém a qualidade da imagem formada não é a mesma, uma vez que o feixe de cor vermelha é menos intenso do que o verde e, por essa razão, as imagens projetadas possuem baixa definição. O suporte do laser pode ser feito de diversas formas, desde que o laser fique o mais fixo e imóvel possível. Cabe ressaltar que o professor deve tomar cuidado para que os alunos fiquem sempre atrás do laser como medida de precaução para evitar eventuais acidentes que podem ocorrer pela interação com o laser.

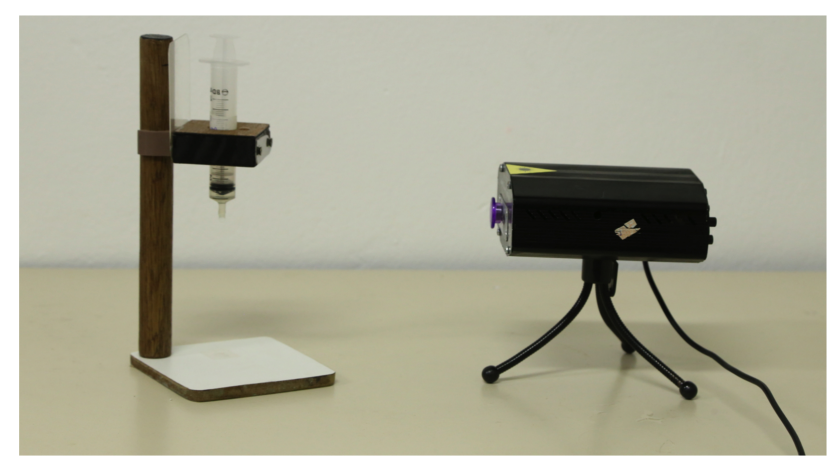

Figura 1: Montagem do aparato experimental. Para a montagem do projetor de gotas é necessário dispor de uma fonte laser, uma seringa e um suporte para a seringa. O feixe de luz produzido pelo laser atravessa diretamente o centro da gota, suspensa pela seringa, de forma a projetar uma imagem ampliada dos microrganismos no anteparo (parede branca). 
Todo o aparato experimental pode ser montado sobre uma mesa plana a uma distância variável, de 0.5 a 3.0 metros de uma tela ou parede branca, onde se formará a imagem. Para a formação da imagem, se coleta uma amostra de água contendo os microrganismos a serem estudados com a seringa e a ajusta no suporte, com cuidado. Em seguida, pressiona-se o êmbolo da seringa para formar uma gota de água (em torno de $2 \mathrm{~mm}$ de diâmetro) no bico. Feito isso, deve-se ajustar a altura do laser para que este passe no meio da gota de água, perpendicularmente à tela. Com isso, o feixe laser se espalhará na tela, tornando-se possível observar o que estiver contido na gota de aguá. As imagens dos microrganismos ali contidas aparecem ampliadas como uma sombra escura, flutuando e se movendo na tela.

Na Fig. 2 apresentamos algumas imagens projetadas de microrganismos, tais como, rotifero e paramecium, coletados de uma amostra de água pela seringa. Dependendo do tamanho dos microrganismos contidos na gota, é possível verificar contornos de franjas de interferência ao redor da sombra
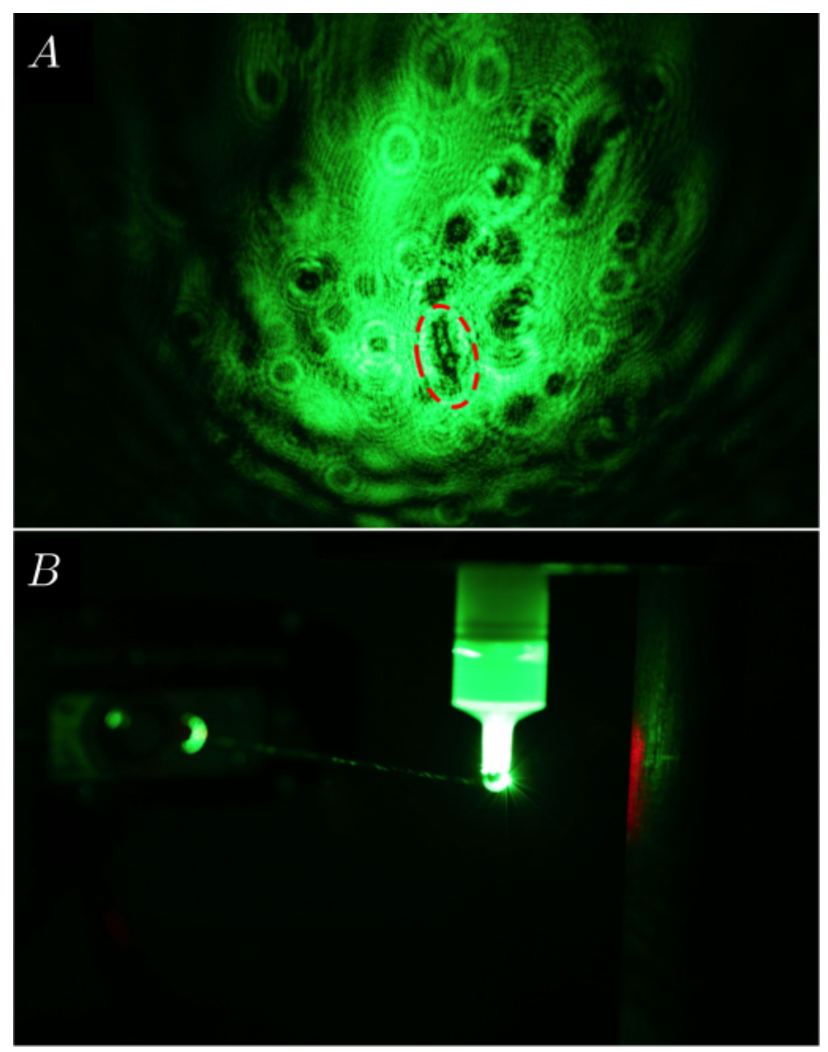

Figura 2: (A) Projeção de microrganismos utilizando o aparato experimental que compõe o projetor de gotas. Em destaque, um microrganismo do gênero paramecium. (B) Detalhe mostrando a interação do feixe laser com a gota de água suspensa pela seringa. projetada. É razoável que pequenos organismos decantem e projetem pontos circulares de franjas de interferência que são gerados pela difração da luz. De uma forma geral, observam-se diversas sombras projetadas que fluem pela gota. Dessas, algumas exibem movimento próprio, porém, em geral, nenhum detalhe estrutural pode ser verificado. No entanto, é possível identificar de forma clara os microrganismos projetados e acompanhar seus movimentos, pois eles apresentam movimentação própria que é facilmente identificada durante a projeção. Nesse experimento, as imagens foram projetadas em uma parede branca lisa a aproximadamente dois metros da gota e fotografadas com uma câmera Canon 6D.

\section{Fundamentação Teórica}

Os principais conceitos teóricos envolvidos no experimento para a formação das imagens se fundamentam na óptica geométrica. A gota formada no bico da seringa possui uma região mais afastada do bico, que pode ser tratada como uma lente esférica. Esse tipo de lente se forma quando uma superfície esférica de raio $R$ se encontra na interface de dois materiais com índice de refração diferentes, $n_{1}$ e $n_{2}$ [3]. De acordo com a Fig. 3, o feixe laser sofre refração duas vezes ao passar pela gota.

A primeira refração ocorre na interface ar-água quando o feixe entra na gota, na qual se encontram diversos microrganismos flutuando, a uma distância $P$ do eixo principal. Ao atravessar a gota, o feixe refrata novamente, na interface água-ar, para formar a imagem na tela a uma distância $P^{\prime}$ do eixo principal. A distância $P^{\prime}$ depende da distância da gota até a tela, $D$, e do ângulo $\phi$ entre o feixe refratado ao sair da gota e o eixo principal, conforme indicado na Fig. 3.

Usando o teorema segundo o qual o ângulo externo de um triângulo é igual à soma dos ângulos internos opostos, nos triângulos (A) e (B) em destaque, da Fig. 3, temos:

$$
\theta=\beta+\phi
$$

$\mathrm{e}$

$$
\theta+\beta=2 \alpha .
$$

Então,

$$
\phi=2(\theta-\alpha) .
$$

Utilizando a lei de Snell para refração, 


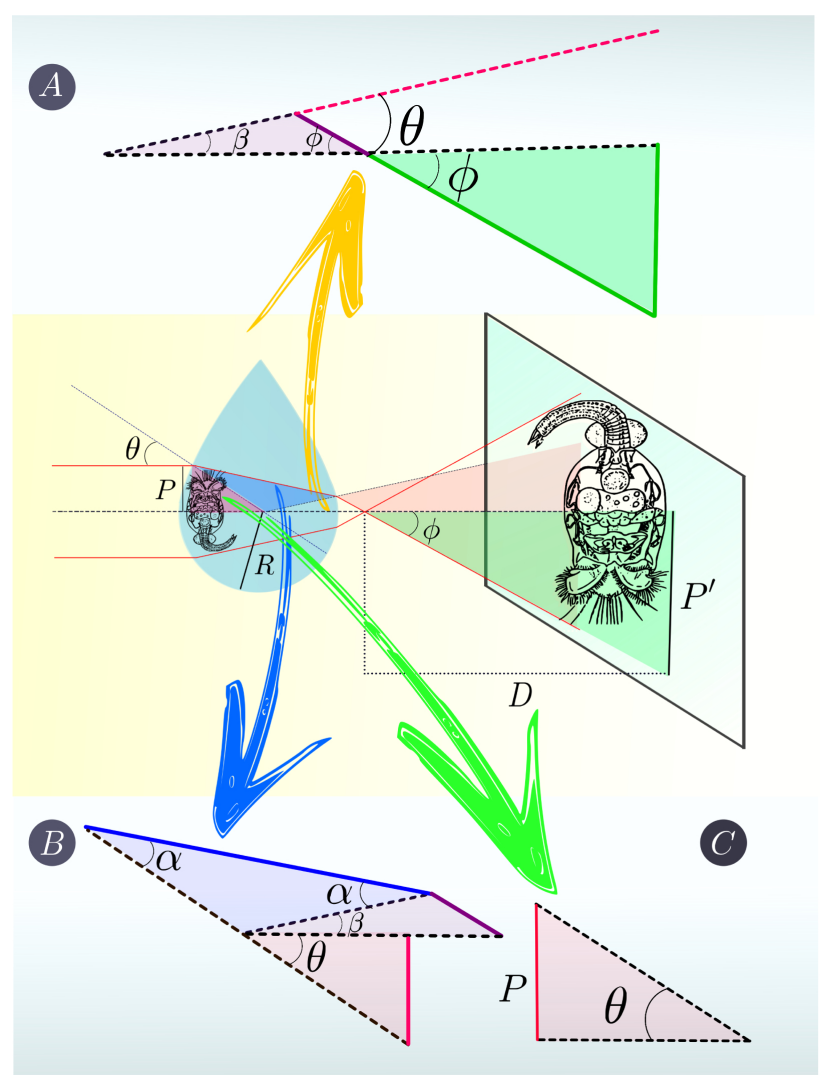

Figura 3: Representação esquemática do projetor de gotas. A gota de água funciona como uma lente esférica, assim a óptica geométrica pode ser aplicada para determinação da formação da imagem no anteparo. A imagem formada é característica de uma lente convergente (real, invertida e maior que objeto), na situação onde o objeto se encontra entre o ponto antiprincipal e o foco. Nos detalhes, especificados em (A), (B) e (C) é possível ter uma visão ampliada dos ângulos formados pelos raios incidentes e refratados com o eixo principal e com a projeção das normais, todos no mesmo plano da superfície da gota.

$$
n_{1} \sin (\theta)=n_{2} \sin (\alpha)
$$

sendo, o índice de refração para o ar e a água, $n_{1}=$ 1.00 e $n_{2}=1.33$, respectivamente. Analisando o triângulo (C) da Fig. 3 vemos que $\sin (\theta)=P / R$, onde $P$ corresponde à metade da altura do objeto, e $R$ é o raio da gota. Dessa forma, a Eq. 4 pode ser escrita da seguinte forma:

$$
\sin (\alpha)=\frac{P}{n_{2} R}
$$

Portanto,

$$
\phi=2\left[\sin ^{-1}\left(\frac{P}{R}\right)-\sin ^{-1}\left(\frac{P}{n_{2} R}\right)\right] .
$$

Para raios paraxiais, tanto $\theta$ quanto $\alpha$ são muito pequenos com relação a um radiano. Logo, podemos aproximar a tangente e o seno pelos próprios valores dos ângulos (em radianos) 3. Dessa forma:

$$
\phi \approx 2 \frac{P}{R}\left(1-\frac{1}{n_{2}}\right) .
$$

A ampliação da imagem formada na tela pela sombra do objeto (microrganismo) possui uma magnificação dada por:

$$
M=\frac{P^{\prime}}{P}=\frac{D \tan \phi}{P} \approx 2 \frac{D}{R}\left(1-\frac{1}{n_{2}}\right) .
$$

Dessa forma, para uma gota com $2 \mathrm{~mm}$ de diâmetro ( $R=1 \mathrm{~mm}$ ), a sombra da imagem formada em uma tela à $2 \mathrm{~m}$ de distância, $D$, do aparato experimental produz um aumento de aproximadamente 1000 vezes com relação ao objeto. A aproximação de pequenos ângulos não é válida no caso do objeto ter um tamanho comparável ao da gota. Nesse caso a expressão para a magnificação é dada usando o valor de $\phi$, dado pela Eq. 6, da seguinte forma:

$$
M=\frac{D}{R}\left[\frac{1}{\rho} \tan \left[2\left(\sin ^{-1}(\rho)-\sin ^{-1}\left(\frac{\rho}{n_{2}}\right)\right)\right]\right],
$$

com $\rho=P / R$ sendo uma relação entre a distância do raio incidente ao eixo principal e o raio da gota, e pode ter qualquer valor entre 0 e 1 [.

No gráfico da Fig. 4 utilizou-se a Eq. 9 para representar a magnificação, $M$, das imagens projetadas em função de $\rho$, para diferentes valores de $D$.

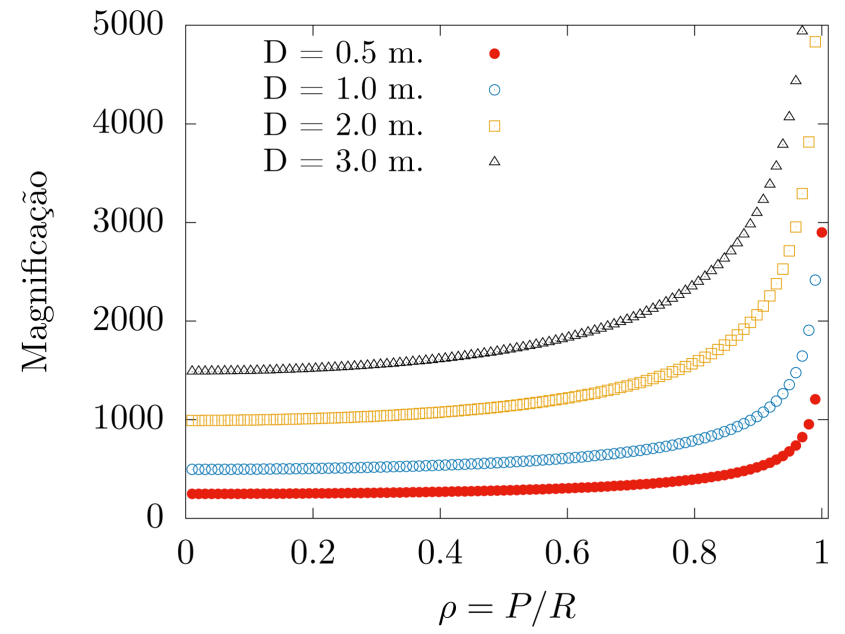

Figura 4: Gráfico da magnificação das imagens projetadas em função da variável $\rho$, para diferentes distâncias da gota ao anteparo, $D$. 
Para todas as curvas do gráfico, o raio da gota foi de $1 \mathrm{~mm}$. A magnificação é aproximadamente constante para valores de $\rho$ em torno de 0.5 , no entanto, à medida que $\rho$ aumenta, a função muda de comportamento, passando a assumir valores de magnificação cada vez maiores. Observa-se que a magnificação da imagem depende de $D$, porém, para cada valor de $D$ o perfil da função se mantém o mesmo. Dessa forma, verifica-se que, para $D=2 \mathrm{~m}$, é possível obter uma magnificação de 1000 vezes o tamanho do objeto, porém, quando diminui-se a distância para 0.5 metro, o valor da magnificação cai por um fator aproximadamente igual a $1 / 4$.

Por fim, vale ressaltar que toda a dedução teórica tem como base assumir a gota de água como perfeitamente esférica. Dessa forma, durante o experimento, recomenda-se ajustar a altura do laser para atravessar a parte inferior da gota, pois, possui uma boa aproximação esférica. A parte superior da gota, mais próxima ao bico da seringa, gera graves distorções nas sombras das imagens 5 .

\section{Proposta de aplicação em sala de aula}

Nesta sessão são propostas estratégias didáticas para utilizar o projetor de gotas em sala de aula. As sugestões aqui apresentadas têm o caráter de apenas demonstrar algumas possibilidades interessantes de como se utilizar o experimento para que os professores se motivem e desenvolvam novas ideias.

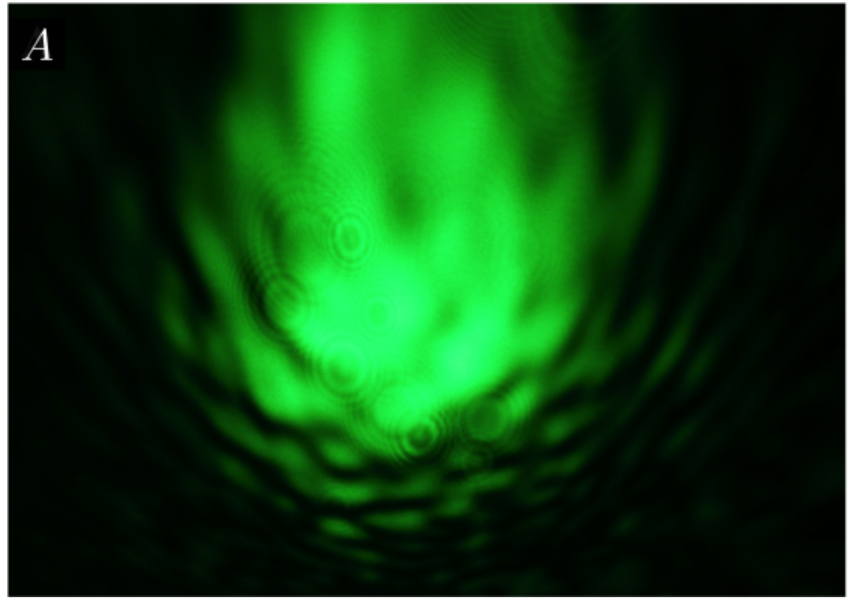

\subsection{Interação entre física e biologia}

Tendo em vista todo o apelo por aulas cada vez mais interdisciplinares, conforme apresentado na introdução desse trabalho, o projetor de gotas é uma ferramenta poderosa para a prática desse tipo de atividade. O experimento tem a capacidade de projetar imagens de diversos tipos de microrganismos armazenadas em água (ver Fig. 20. Sendo assim, os professores de física e biologia podem planejar aulas utilizando amostras de águas de diferentes localidades como, rios, lagos, aquários domésticos ou até mesmo o mar, assim como diversos tipos de microrganismos que estejam em conformidade com o conteúdo a ser ministrado em aula. Assim, os docentes podem apresentar conceitos biológicos sobre os microrganismos, a água e toda a ótica envolvida no formação da imagem que norteiam o experimento.

Dentre essas várias propostas possíveis, apresentaremos uma sugestão de experimento que vai nessa linha. A ideia do experimento é apresentar aos alunos a quantidade de microrganismo que se acumulam em nossas mãos, para então enfatizar a importância de lavá-las durante o dia. Para isso, utilizamos uma amostra de água filtrada, obtida diretamente da torneira e armazenada em um vasilhame, e seguimos toda a metodologia apresentada anteriormente para a projeção da imagem da amostra. A Fig. 5 (A), ilustra o que se observa com essa metodologia. O que se vê é praticamente o espalhamento do laser na tela, com nenhum tipo de microrganismo na gota de água. Em seguida, o professor pode pedir para que um aluno lave as mãos no recipiente onde se

Figura 5: Projeção de amostra de água em duas situações. Para formar o padrão da imagem evidenciada em (A), recolheu-se uma amostra de água natural. A imagem mostrada em (B) foi obtida após um dos pesquisadores desse trabalho lavar as mãos na amostra de água filtrada. 
encontra a amostra de água utilizada. Depois disso, pega-se, com a seringa, um porção dessa nova amostra e se leva ao aparato experimental. O resultado disso pode ser visto na Fig. 5 (B). Observa-se um padrão de imagem completamente diferente do anterior. Isso se deve à quantidade de microrganismos e sujeiras que se acumulam em nossas mãos e que, quando lavadas, se depositam na amostra de água.

Essa proposta de utilização do experimento já foi realizada pelo nosso grupo de pesquisa em diversas exposições didáticas feitas em colégios e faculdades na cidade de São Paulo. A reação dos alunos quando veem a diferença na imagem depois de lavarem as mãos é notável e desperta o interesse deles a respeito da problemática e fenomenologia envolvidas no experimento. A higienização das mãos é um tema de muita importância na área da saúde e diversos colégios têm feito campanhas educativas de conscientização para a prevenção da proliferação da gripe H1N1. Professores e pais de alunos nos relataram que não é fácil para as crianças entenderem o porquê de lavarem as mãos, tendo em vista, a dificuldade delas para conceber o mundo microscópico, pois, trata-se de algo que está fora do alcance de percepção visual humana. Dessa forma, o projetor de gota traz à tona esse universo e o resultado é impactante e pode contribuir de forma positiva aos professores, pais e diretores de colégios na campanha para higienização das mãos.

\subsection{Explorar o conceito de calor em uma aula de óptica}

A proposta aqui é mostrar uma estratégia para abordar o conceito de calor, em sala de aula, com o projetor de gotas. Sabe-se que o conceito de calor é um dos mais difíceis de se apresentar aos alunos. Diversos estudantes, tanto de ensino médio quanto de graduação, apresentam grandes dificuldades para diferenciar calor de temperatura [6]. São muitos os trabalhos encontrados na literatura, onde pesquisadores examinam como é abordado o conceito de calor em livros didáticos do Ensino Médio. A proposta aqui não é se aprofundar na assunto sobre a definição de calor, e sim mostrar como o projetor de gotas pode ajudar a elucidar esse conceito durante uma aula. Entretanto, estudos mais aprofundados sobre o assunto podem ser vistos nas seguintes referências $6[9]$.

Inicialmente, deve-se escolher uma amostra de água para ser projetada na tela. O intuito aqui é gerar uma diferença de temperatura próximo da gota para que possa ocorrer uma transferência de calor para ela. Seguindo o esquema da Fig. 2, podese utilizar amostras com alguns microrganismos, como por exemplo, rotíferos ou paramecium, ou até mesmo usar a mesma metodologia da seção anterior e pedir para um aluno lavar as mãos em um recipiente com água para utiliza-la como amostra. Com a imagem projetada na tela, aproxima-se da gota alguma fonte de calor, como por exemplo, um bico de solda (ver Fig. 6), (não se deve utilizar fósforo ou isqueiro, pois, pode-se evaporar a gota). Com isso, o que se vê na tela com a imagem projetada, é um movimento muito mais rápido dos microrganismo na gota. De acordo com a seguinte definição: Calor é a energia transferida graças a diferença de temperatura [10, pode-se criar um debate em sala de aula para se discutir o que está acontecendo e por que os microrganismos se movimentam de forma mais rápida. Essa é uma proposta interessante para se debater o conceito de calor sem defini-lo de início, fazendo com que, através do experimento, os alunos possam chegar a essa definição pela observação do fenômeno. Ainda nesse contexto, pode-se discutir toda a parte de transferência de calor da solda para gota, variação de energia e temperatura.

\subsection{Abordagem de conceitos de ótica física}

Uma das grandes discussões hoje em dia sobre o conteúdo de óptica no ensino médio é que praticamente tudo o que se ensina é relacionado à óptica geométrica e pouca importância tem-se dado a óptica física 2, 11]. A óptica geométrica é fundamental para o entendimento de diversos fenômenos, tais como, reflexão e refração da luz e a formação de imagens em espelhos e lentes [2, 3, 12]. Porém, diversos fenômenos ondulatórios importantes deixam de ser abordados como, por exemplo, difração, interferência, polarização e espalhamento, que só podem ser explicados tratando a luz como onda. Dessa forma, torna-se evidente a necessidade de propostas didáticas para abordagem desse conteúdo no ensino de óptica, pois, esse conhecimento é fundamental para que o aluno possa entender o mundo em que vive e as tecnológicas atuais, o que dá um significado mais concreto para esse conteúdo [1,4,12 . Sendo assim, um experimento simples e de baixo custo, como o projetor de gotas, é uma excelente proposta didática para se abordar conceitos de ótica física como difração e interferência. 


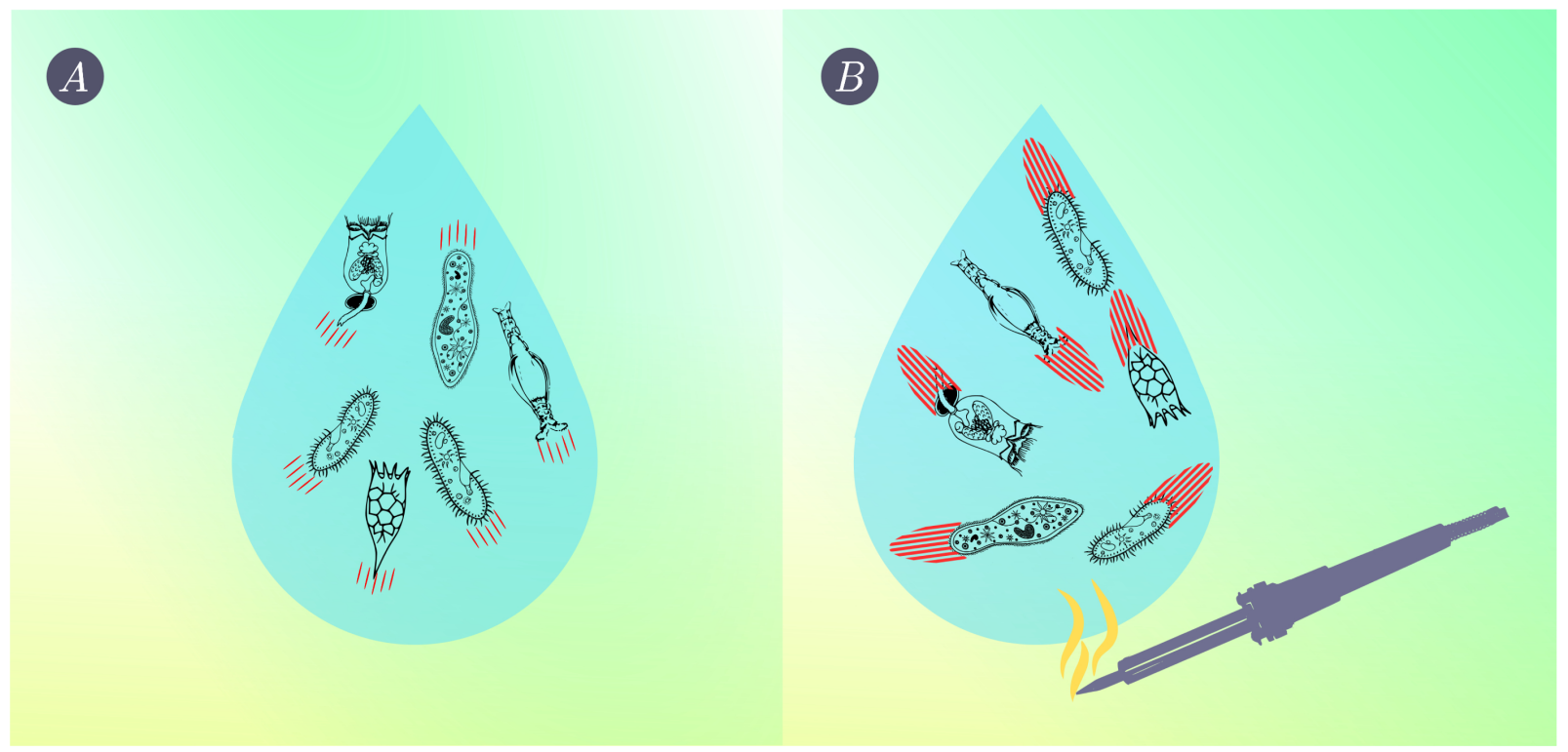

Figura 6: Representação esquemática sobre o efeito do aumento da temperatura no movimento dos microrganismos presentes na gota de água. Em (A), os microrganismos contidos no interior da gota de água se deslocam com velocidade característica, enquanto que ao aproximarmos um bico de solda quente próximo à gota, (B), o calor se propaga por convecção, fazendo com que os microrganismos adquiram velocidades maiores, se deslocando por todas as direções em um movimento caracteristicamente browniano.

Na Fig. 7 pode se verificar que pequenas partículas suspensas na gota de água geram franjas de interferências visíveis na tela onde se formam as imagens. A luz do feixe laser, ao colidir com esses pequenos objetos suspensos, difratam e se interferem de forma construtiva e destrutiva, gerando as imagens vista na Fig. 7 (A) e (B).

Portanto, vê-se que é possível utilizar o experimento do projetor de gotas para se abordar conceitos, tanto de óptica geométrica, para formação das imagens, como de óptica física, para os fenômenos ondulatórios visíveis mostrados na Fig. 7. Assim, uma sugestão interessante seria o professor utilizar o experimento para explicar os diversos fenômenos ópticos envolvidos e, dessa forma, mostrar o limite de validade da óptica geométrica, para então adentrar nos conceitos de ondulatória.

\subsection{Possibilidades a serem exploradas}

Atualmente, se discutem diversas propostas didáticas para inserção de conteúdos de física moderna no ensino médio [13. São vários os fatores que dificultam essa inserção, que vão desde, a má formação docente,
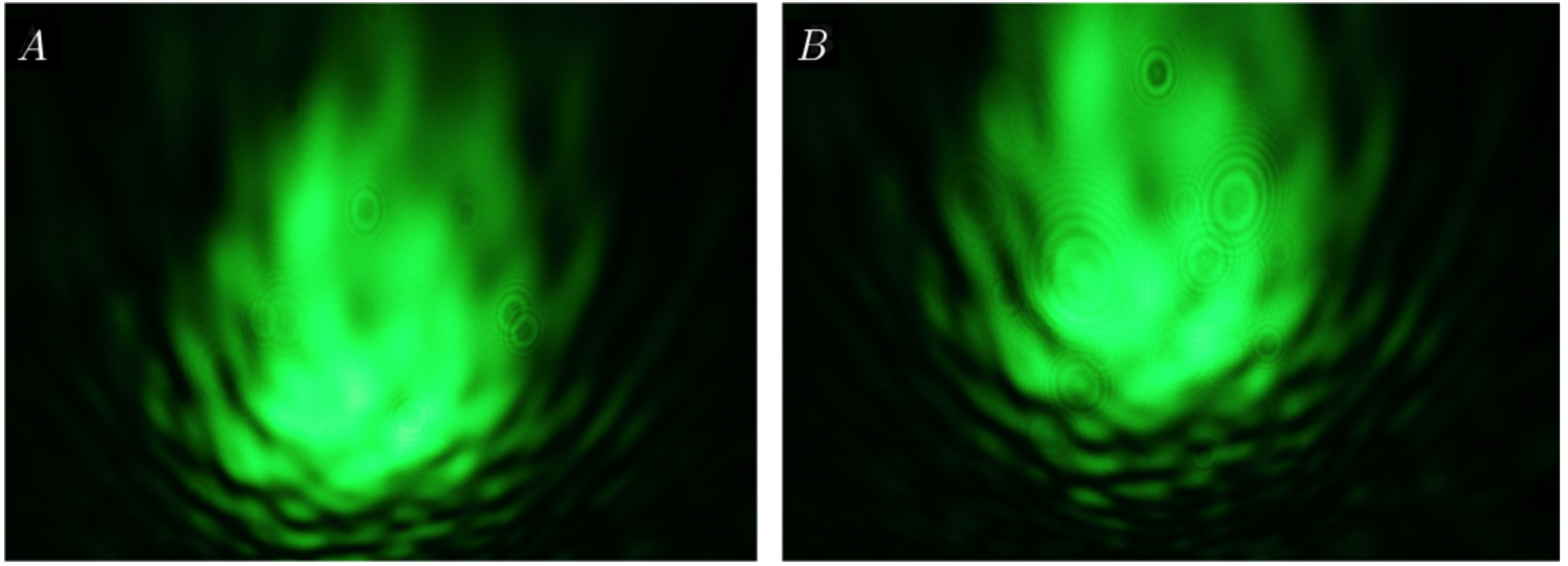

Figura 7: (A, B) Padrões de franjas de interferência obtidas em dois momentos distintos da mesma amostra de água. Nessa amostra, a água continha pequenas quantidades de grãos de areia, responsáveis por gerar a difração da luz. 
professores de outras áreas que lecionam física, e até mesmo a falta de experimentos simples que possam ilustrar conceitos teoricamente complexos para alunos de ensino médio 11 13. Nesse sentido, o experimento aqui proposto pode ser uma boa maneira de se inserir conceitos de física moderna, através de um conteúdo relativamente complexo, que é o movimento browniano.

A primeira observação desse tipo de movimento foi verificada em 1828 pelo botânico inglês Robert Brown, daí o nome "movimento browniano" 14. Ele verificou que pequenas partículas em suspensão apresentavam um movimento irregular. Mais especificamente, Brown observou o movimento incessante e errático de partículas de pólen dissolvidas em água 14. Trabalhos que abordam, com maior profundidade, os fundamentos teóricos do movimento browniano, assim como sua importância histórica para o desenvolvimento da física moderna, podem ser encontrados nas referências [14 16]. Por mais que não faça parte das aplicações experimentais apresentadas nesse trabalho, acreditamos ser possível utilizar o projetor de gotas para se abordar o movimento browniano de forma qualitativa.

Seguindo a metodologia experimental aqui apresentada, seria possível utilizar partículas pequenas que ficassem suspensas em água sem se diluírem, e com uma câmera fotográfica fazer um ajuste para capturar uma quantidade de imagens em um certo intervalo de tempo. Realizando diversos testes, acreditamos que seria possível, através das imagens adquiridas, identificar a posição de uma determinada partícula em cada uma das imagens e verificar o comportamento aleatório do seu movimento. Dessa forma, o professor poderia seguir um roteiro semelhante ao aqui sugerido e utilizar o microscópio de gotas em sala de aula para discutir o conceito de movimento aleatório e abordar a teoria envolvida no movimento browniano. Essa experiência pode ser utilizada tanto no de ensino médio quanto superior, dependendo do aprofundamento teórico que o professor deseja abordar.

\section{Conclusão}

Conforme proposto, vemos que um experimento relativamente simples e de baixo custo é capaz de ser utilizado em diversas abordagens para tornar uma aula mais dinâmica e interessante. A utilização do projetor de gotas, pode vir a suprir diversos obstáculos para utilização de experimentos em sala de aula, tendo em vista que são diversas as escolas de ensino básico que não possuem um laboratório didático devido ao custo. Um outro equipamento que poderia realizar um estudo semelhante seria um microscópio. Porém, além do custo para se adquirir um, as observações realizadas teriam que ser individuais, e dificilmente todos os alunos veriam a mesma coisa, o que poderia gerar dúvidas se o que ele está vendo é realmente o que o professor está explicando. Portanto, o experimento aqui proposto supera essa dificuldade, uma vez que todos podem ver o que está sendo projetado e o professor teria mais facilidade e dinamismo para conduzir a aula. Dessa forma, acreditamos que o projetor de gotas pode ser utilizado com facilidade e que é capaz de tornar as aulas mais interessantes e ajudar no contexto científico do ensino básico do nosso país.

\section{Agradecimentos}

Os autores agradecem à professora Eliana Dessen do Instituto de Ciências Biomédicas da Universidade de São Paulo pelo fornecimento dos microrganismos utilizados como um dos objetos de estudo deste trabalho. Ao professor Claudio Furukawa, do laboratório didático do IFUSP, pela colaboração na montagem e cessão dos equipamento e, por fim, ao fotógrafo Fabio Miyata pelas aquisições das imagens para o presente trabalho.

\section{Referências}

[1] V.S. Bagnato and S. Pratavieira, Revista Brasileira de Ensino de Física 37, 4206 (2015).

[2] L.A. Souza, L. da Silva, J.A.O. Huguenin and W.F. Balthazar, Revista Brasileira de Ensino de Física 37, 4311 (2015).

[3] H. Young and R. Freedman, Física IV: Ótica e Física Moderna (Editora Pearson Education do Brasil, São Paulo, 2009), $12^{\mathrm{a}}$ ed.

[4] J.P. Gircoreano and J.L.A. Pacca, Caderno Brasileiro de Ensino de Física 18, 26 (2001).

[5] G. Planinsic, Physics Teacher 39, 76 (2001).

[6] O.H.M. da Silva, C.E. Laburú and R. Nardi, Caderno Brasileiro de Ensino de Física 25, 383 (2009).

[7] R. Axt and M.E. Brückmann, Caderno Brasileiro de Ensino de Física 6, 128 (1989).

[8] G.F.L. Ferreira, Revista Brasileira de Ensino de Física 28, 125 (2006).

[9] J.M.F. Bassalo, Revista Brasileira de Ensino de Física 14, 29 (1992). 
[10] P.A. Tipler and G. Mosca, Física para Cientistas e Engenheiros. Vol. 1: Mecânica, Oscilações e Ondas, Termodinâmica (LTC, Rio de Janeiro, 2013), $6^{\mathrm{a}}$ ed.

[11] H.J. Kalinowski and N.M.D. Garcia, Caderno Brasileiro de Ensino de Física 7, 64 (1990).

[12] J.L.P. Ribeiro and M. F. S. Verdeaux, Revista Brasileira de Ensino de Física 34, 4403 (2012).

[13] M.A. Cavalcante and C.R.C. Tavolaro, Caderno Brasileiro de Ensino de Física 18, 298 (2001).

[14] S.R.A. Salinas, Revista Brasileira de Ensino de Física 27, 263 (2005).

[15] J.M. Silva and J.A.S. Lima, Revista Brasileira de Ensino de Física 29, 25 (2007).

[16] J.S. Figueira, Revista Brasileira de Ensino de Fisica 33, 4403 (2011). 